\title{
Christoph Strohm (dir.), Reformation und Recht
}

\section{Gérald Chaix}

\section{OpenEdition \\ Journals}

Édition électronique

URL : http://journals.openedition.org/ifha/9223

DOI : $10.4000 /$ ifha. 9223

ISSN : 2198-8943

Éditeur

IFRA - Institut franco-allemand (sciences historiques et sociales)

\section{Référence électronique}

Gérald Chaix, « Christoph Strohm (dir.), Reformation und Recht », Revue de I'IFHA [En ligne], Date de recension, mis en ligne le 14 juin 2018, consulté le 24 septembre 2020. URL : http:// journals.openedition.org/ifha/9223 ; DOI : https://doi.org/10.4000/ifha.9223

Ce document a été généré automatiquement le 24 septembre 2020.

(C)IFHA 


\title{
Christoph Strohm (dir.), Reformation und Recht
}

\author{
Gérald Chaix
}

\section{RÉFÉRENCE}

Christoph Strohm (dir.), Reformation und Recht. Ein Beitrag zur Kontroverse um die Kulturwirkungen der Reformation, Tübingen: Mohr Siebeck, 2017, 219 p., $14 €$ 
Moins volumineux, dépourvu d'index des matières, l'ouvrage collectif coordonné par Christoph Strohm, professeur d'histoire ecclésiastique à l'université de Heidelberg (Heidelberger Forschungszentrum für Internationale und Interdisziplinäre Theologie), apporte cependant une contribution importante à la controverse sur les effets culturels de la Réformation. Il rassemble les sept contributions présentées par les auteurs, pour la plupart historiens du droit, lors d'un colloque organisé à Berlin les 26 et 27 février 2016. Aujourd'hui professeur d'histoire à l'université d'Erfurt, Cornel A. Zwierlein reprend à frais nouveaux - pertinence géographique et validité méthodologique - le concept de confessionnalisation. Pour C. Zwierlein, le noyau de la confessionnalisation n'est ni l'État ni la réalité sociale mais cet « empirisme» - enregistrement,

\section{Reformation} und Recht

Herausgegeben von

Christoph Strohm

standardisation, précision terminologique - qui agit dans et sur les relations entre État et Églises, à l'occasion de l'institutionnalisation en phase avec lui. Déjà peu pertinent au-delà des frontières d'un Empire lui-même territorialisé, le concept perd tout intérêt au sein même de l'Europe s'il s'agit d'étudier les relations avec les « enclaves » juives, disséminées ici ou là, ou, sur les périphéries, les relations avec l'empire ottoman. Il en est de même a fortiori dans une perspective extra-européenne (tableau, p.51). Professeur émérite, l'historien du droit Michael Stolleis éclaire sobrement les relations entre la Réformation, le développement du droit et celui de l'État. Il rappelle le rôle du droit (Verrechtlichung) dans la genèse de l'État moderne (XIII ${ }^{\mathrm{e}}-\mathrm{XVI}^{\mathrm{e}}$ siècles). Il souligne l'influence de la Réformation sur le droit matrimonial et sur le processus de sécularisation, l'affirmation des villes libres d'Empire (freie Reichsstädte) et des territoires, mais aussi l'organisation de l'Empire, depuis la Bulle d'or (1356) jusqu'à l'ordonnance concernant la cour aulique (Reichshofratordnung, 1654). La dimension confessionnelle est visible tout particulièrement dans la formulation du «droit de résistance " et l'auteur souligne le rôle joué par les juristes protestants dans le développement de la réflexion politique concernant l'Empire (Reichspublizistik). Historien du droit à Halle-Wittenberg, Heiner Lück s'est concentré sur l'apport des juristes de Wittenberg à l'essor du droit européen et à la formation d'un droit matrimonial évangélique au cours $d u X \mathrm{XV}^{\mathrm{e}}$ siècle. Il rappelle la qualité des juristes (Melchior Kling, Johannes Schneidewin, Matthäus Wesenbeck), l'apport de Luther luimême en ce qui concerne la conception du mariage, et finalement le rôle du prince territorial par le biais des ordonnances ecclésiastiques (Kirchenordnungen).

Jeune historien du droit à l'université de Louvain, Wim Decok a pris en considération la contribution catholique au développement du droit à l'époque moderne. Il rappelle que l'autodafé du 10 décembre 1520 - au cours duquel sont brûlés non seulement la bulle pontificale d'excommunication de Luther mais aussi des ouvrages de droit canon et la 
Summa de casibus conscientiae du franciscain Angelo Carletti de Chivasso - atteste le processus de codification juridique de la morale chrétienne dans l'Église catholique romaine. Il évoque les débats sur le droit de migration et sur l'assistance aux pauvres, ainsi que le respect des contrats par-delà les frontières confessionnelles. La séparation $\mathrm{du}$ droit et de la morale, dont le fondement est désormais biblique, est un acquis de la Réformation partagé par les deux confessions. Les théologiens catholiques ont ainsi le champ libre pour continuer de marquer le développement du droit. Christoph Strohm a pour sa part étudié la dynamique créée par la concurrence confessionnelle. L'intérêt porté à l'histoire et à l'historicisation du droit en est un des effets. Il souligne ainsi que le développement du droit est étroitement lié aux processus de confessionnalisation mais aussi de sécularisation et évoque la figure de Francisco Suárez (1548-1617). Historien du droit à Erlangen, Heinrich De Wall s'est penché sur les formes nouvelles prises par le droit canonique dans le monde évangélique et plus précisément sur le passage du droit canon aux ordonnances ecclésiastiques promulguées par le prince territorial. Sous la forme de dix-sept thèses, Axel Freiherr von Campenhausen, professeur émérite à l'université de Munich, a tiré les conclusions du colloque, soulignant ainsi la fécondité de la thématique et suggérant de nouvelles pistes de recherches.

INDEX

Index chronologique : Période moderne

Thèmes : Histoire religieuse ; Histoire des mentalités

\section{AUTEURS}

GÉRALD CHAIX

Université de Tours, UMR 7323 